\title{
¿ANTROPÓLOGOS VS. MISIONEROS? A propósito de una carta de Joseph Goetz a Juan Bottasso
}

Marie Astrid Dupret, J. Sánchez Parga

Joseph Goetz, reconocido antropólogo alsaciano, fue misionero en África (Tchad). De sus clases dictadas en Roma en los años setenta viven hoy en Ecuador cuatro alumnos, dos de ellos son los hermanos Bottasso. Una carta del "gran" Goetz de hace más de 30 años (1977), dirigida a Juan Bottasso a propósito de un antiguo e inacabable debate sobre el cristianismo o la cristianización de las religiones primitivas, nos ha sugerido replantear hoy dicha cuestión. Hemos pedido al P. Juan un comentario actual y retrospectivo de aquel texto; otro a Marie Astrid Dupret, quien siguió un curso de Goetz, cuando realizaba su doctorado en sumeriología en el Instituto de Estudios del Antiguo Oriente; y otro a José Sánchez Parga entonces doctorando en el Instituto Bíblico Oriental.

\section{Texto de la Carta de Goetz}

Lyon, Francia, 16 de mayo de 1977

Padre Bottasso, no es fácil ni sencillo responder a sus inquietudes y a las de sus cofrades acerca de la catequesis de los Shuar. Pero, no me parece que sea posible comparar, $y$ aún menos equiparar el Antiguo Testamento y las tradiciones míticas de los Shuar o de otros. Cuando más pueden estar en el mismo nivel por el tipo de ritos y la sicología (en parte). Pero respecto de las "representaciones religiosas", en cambio, lo que corresponde en el Antiguo Testamento a las tradiciones religiosas de los amazónicos, es precisamente aquello contra lo cual el Antiguo Testamento lucha con violencia profética.

El anuncio propio del Antiguo Testamento, es la irrupción del Dios "totalmente otro" en la historia de un pueblo, y a través de éste, en la historia de todo hombre. Éxodo, desde el Sinaí del Zarzal ardiente al Sinaí del Decálogo, que se desarrolla progresivamente, con exclusión de cualquier otra Potencia, de las preocupaciones y esperanzas de los hombres. Luego, con una especie de flash back, el propio Abraham se define a sí mismo como uno que debería "salir de su tierra", anticipando la salida de Egipto.

El anuncio del Nuevo Testamento, en cambio, parece menos violento; incluso San Pablo, en la 
Carta a los Colosenses (2-3), admite la existencia de potencias ("elementos del mundo"), pero dice él también, que Cristo está por encima de todo, y que es el Señor. Así, ya a priori me parece imposible identificar a Cristo con cualquier figura mítica, y con mayor razón en el caso de los Shuar, ya que estas figuras míticas son también, divinidades "actuales".

En cuanto a la pastoral eucarística, aplicación de tales promesas, el problema es más complejo: tenemos una doble buena nueva mejor dicho, unas verdades a entregar (Dios y Cristo), pero debemos expresarla con un lenguaje comprensible.

El problema del lenguaje (no del idioma, sino del sistema de expresión), según parece, existía también en el Antiguo Testamento, en el sentido de que emplea ciertas palabras (y ritos) que no tenían el significado exacto exigido por el monoteísmo, porque estaban tomadas del politeísmo. Pero, se suponía que tanto las palabras como los ritos, cambiarían su significado con el progreso de la enseñanza de los profetas y de la vida religiosa de la comunidad (Lo dice claramente Gregorio Magno en la carta a Amasio). Con frecuencia se tiene la impresión de que Yahvé (cuyo nombre no era conocido por los Padres) era un dios (entre los dio- ses), entre los otros. Pero sin duda hubo una evolución hasta que se entendió que Él no era como los otros dioses, eran unas "nadas". Dios solo es Dios, Verdadero Dios. -se puede notar que- si "Él" es aceptado, los "Baal" (correspondientes a los Nunkui y compañía de ustedes), son rehusados. Así pues, hay una pedagogía, pero con una orientación muy precisa.

Entonces, si en el lenguaje usado, -que era el lenguaje preexistente-, para que Dios no parezca ser algo extranjero hay algunas concesiones provisionales; para las ideas, no hay ninguna concesión: Dios del Antiguo Testamento para los judíos era algo nuevo, único. Aunque a veces en el Antiguo Testamento y en el Nuevo Testamento se admite la presencia de Potencias, de los "dioses" (o sea, "espíritus"), siempre Dios los domina a todos y eventualmente los inutiliza. Ni Dios ni Cristo son uno de ellos, y éste es el "gran misterio" que quedará oculto hasta ese momento (o disimulado por los paganos: Epístola a los Romanos). Una simple ecuación Nunkui-Dios-Cristo, sin advertencias previas, sería una traición. Las figuras míticas pueden a veces considerarse una "preparación evangélica”, y también como profecías, pero evangélicas, jamás. A mí me gusta decir que las religiones cósmi- 
cas son "misterio pascual", pero "sin Cristo". Debemos constatar que las religiones paganas (con la única excepción de las religiones decadentes del sincretismo helenístico) no tienen la idea de "salvación", no sienten la necesidad de salvación, ya que sus modelos están situados en el pasado (que basta conservarlo), mientras que los de modelos bíblicos están situados en el futuro (parusía).

A este punto debemos señalar algunos datos de la Etnología:

"Es un hecho que, en la Amazonía, se encuentra difícilmente la idea de Dios (menos en casos recogidos por C. Zerries en las "Religiones Amerindiennes" de Krickberg, etcétera). Eso se debe probablemente al hecho de que los pueblos de la selva tropical no tienen una visión espacial amplia del Mundo. Los africanos de la selva tienen una idea precisa de Dios, pero probablemente eso se deba a que tienen sus orígenes fuera de la selva. Así pues, para la mayoría de los amazónicos, Dios es una auténtica novedad.

Estos amazónicos son "politeístas" sin la idea de los Grandes Politeísmos de una divinidad "allende los dioses”. Y sus mitos no se refieren a figuras míticas arquetipos del hombre, se refieren, en cambio, a unos "Espíritus", potencias actuales de tipo animístico. Entonces, ninguna de éstas es un "arquetipo mítico" que podría ser una anticipación de Cristo.

Para merecer la dignidad de Dios, no basta que un espíritu sea el primero por su potencia entre (otros) muchos. Un "ser supremo... (palabra muy ambigua) no es automáticamente Dios por ser superior a los demás. Debe ser el Creador de los demás y tener una soberanía absoluta, universal, por encima de cualquier potencia, ser "el Señor". Si esta idea es una novedad, no se la puede callar, especialmente si se usa un nombre ya cargado de otras ideas. E incluso, más cuando se trata de Cristo. Allá donde no existe la idea de Dios, no se puede tener una idea correcta de Cristo (no en vano Cristo nació en un pueblo que ya era fanáticamente monoteísta... Así, el problema era claro).

No se puede afirmar categóricamente que es imposible hacer surgir la idea visión de Dios en unas mentes animistas. ¿Cómo podría subsistir un mundo de Potencias, a menudo antagonistas, si no hubiera una Potencia total, universal, que mantenga un mínimo de coherencia aun dejándoles a los, "elementos" una amplia autonomía? Hay unos casos "cuando los espíritus ya no pueden hacer nada más”, y a pesar de todo el mundo sigue igual, entonces se recu- 
rre a Dios, como dicen también los pueblos de la Selva africana o hindú (carestía, esterilidad, epidemias).

En conclusión, distingamos clara y explícitamente el problema del lenguaje y el problema del anuncio del contenido de la Buena Nueva, o sea de la existencia del Dios Verdadero (si ya no lo tienen) y la verdad de Cristo.

No se debe caer en ciertos excesos de la Teología de la Liberación, cuando afirma que cualquier "praxis" de la justicia y el desarrollo del hombre, es realizada por Cristo. Tampoco, en los excesos de ciertas teologías de las religiones, cuando parecen decir que cualquier apertura del hombre al mundo espiritual, es salvífica por sí misma. A los combonianos (en Nigeria, hace dos años), en nuestra presencia, un antropólogo no cristiano (Lanternari) les decía que si nosotros no llevamos la Biblia, nada tenemos que hacer entre esta gente. África ya tiene a Dios pero debe entrar a la historia; Cristo, empero, es una novedad absoluta, ya que no lleva solamente la cultura, como los héroes, sino un nuevo sentido del destino del hombre. Espíritus y héroes organizan la vida terrenal, no "salvan".

Intenté contestar a la interrogante globalmente. Acaso pueda contestar "a la americana", con unos "sí" o "no", en ciertos puntos de su carta.
Tradiciones míticas Shuar = Antiguo Testamento. Respuesta: No.

Cristo dijo: "Ustedes con sus tradiciones arruinaron la ley de Dios".

¿Historia Salvífica completa? Respuesta: No. Ni siquiera parcialmente salvífica: escolarizan unos "elementos" y encierran al hombre en el mundo terrenal, biológico y cultural.

Nunkui es un ser de este mundo, aunque sea poderoso y benéfico. Cristo dice: "Yo no soy de este mundo..." (Nunkui podrá llegar a ser algún día, la palabra para decir "Dios", a condición de que queda bien claro que es Dios. Pero, para Cristo, "no hay otro nombre dado a los hombres para salvarlos". Y cuando Nunkui sea igual a Dios, los pequeños nunkui podrán ser "ángeles" o "pequeños santos". Yo tracé somera y sintéticamente estas ideas en el artículo "dios lointain et Puissances proches" ("Dios lejano y Potencias cercanas", n. d. tr). Stud. Mis. 1974 (este artículo contiene también una referencias y artículos anteriores, en Stud Mis). También hablé de esto anteriormente, en Brillant et Aigrain. Histoire de Religions Vol. V, no recuerdo las fechas. También Eliada puede ayudar. Tratado cap. Y el mito del eterno retorno. 
Le deseo a usted que porta de Roma con ideas claras pero no con soluciones simplistas. Y no es posible transferir a la Amazonía reflexiones y soluciones hechas en África. Pero ustedes están conscientes: de su propia situación, y yo estimo mucho sus capacidades.

Le saludo cordialmente en Cristo.

Y. Goetz

Posdata (continúa el mismo Goetz en la carta).

Si su Nunkui (masculino o femenina) sigue siendo un grave problema de mentalidad, la palabra pudiera perfectamente significar, por extensión, lo que vosotros llamamos Espíritus, o sea Seres o Potencias limitadas, especializadas, numerosas, pero siempre con el defecto de la universalidad. Les falta la idea de que una multitud supone algo que les de cierta unidad...

La idea de la encarnación de Nunkui o de algunos nunkuis es peligrosa también porque pueden tener la idea de que todo niño, o de muchos niños sean el producto del ingreso de un "espíritu" en el seno de la mujer. Entonces la formulación del Catecismo Shuar significaría que Cristo es un hombre cualquiera, un hombre sencillo, con la única diferencia de que, de él se narran muchas historias: un hombre excepcional y nada más.
Desde todos los puntos de vista me parece genial introducir en la cabeza de los Shuar unas nociones que evidentemente faltan. Se trata de no hacer un discurso filosófico, sino un discurso muy concreto.

(Copia de la carta escrita de Lyon en italiano por el mismo Goetz, como respuesta a ciertas dudas acerca de la forma de introducir los mitos y tradiciones Shuar en la catequesis)

\section{Comentario de Juan Bottasso}

Los Documentos del Vaticano II, que han creado en la Iglesia Católica un movimiento de remoción como no se veía desde el Concilio de Trento, no nacieron de la nada. Muchos obispos y los expertos que los asesoraban desde décadas, entre debates y no pocas tensiones, llevaban adelante un replanteamiento de casi todos los puntos de la teología católica. Los nuevos descubrimientos científicos pedían replantear las relaciones entre fe y ciencia.

El mundo ya estaba en pleno camino hacia la globalización y se perfilaban no sólo mayores contactos entre las civilizaciones, sino el peligro de auténticos choques. Era obvio que el tema de las relaciones con las demás religiones exigiera un nuevo enfoque. No se podía seguir repitien- 
do, sin matices, el viejo axioma "fuera de la Iglesia no hay salvación".

Los cardenales Jean Damiélou, Henry de Lubac y Urs von Baltasar, elaboraron la teoría de la "finalización": las diferentes religiones representan la aspiración íntima del ser humano a la unión con la divinidad. De esta manera, todas las religiones tienen un valor positivo y pueden reconocerse como mediaciones salvíficas. Es decir, por medio del Espíritu; Cristo se hace presente en el creyente no cristiano, más allá de las fronteras visibles de la Iglesia, tanto a nivel individual como en las diferentes religiones.

Karl Rahner fue un poco más allá, para él las diferentes religiones son portadoras de valores salvíficos, es decir, a través de ellas se manifiesta la presencia de Cristo. La autocomunicación de Dios se ofrece a todos los hombres en cuanto él quiere que "todos los hombres se salven (1 Tim 2,4). Los caminos de Dios, según Rahner, son anchos y numerosos (teoría de los cristianos anónimos).

El calor del debate ayudó a redescubrir afirmaciones que ya habían resonado en los primeros siglos, como las de la presencia de las "semillas del Verbo" en todas las culturas.

El Decreto "Ad Gentes", sobre la actividad evangelizadora de la Iglesia, hizo suya esta doctrina.
A primera vista parecería tratarse de un pequeño detalle, pero, en la práctica, cambió radicalmente la praxis misionera. Mientras por siglos ésta se había inspirado en la imagen del sembrador y del campo, ahora esta comparación se volvió inaceptable. En efecto, cualquier agricultor, antes de echar la semilla, limpia con cuidado el terreno de cualquier otro tipo de vegetación y después cuida constantemente el sembrío para que las "malas hierbas" no vuelvan a sofocar el trigo. Para predicar el Evangelio había que extirpar todas las formas preexistentes de religión, entendidas como supersticiones y falsas creencias.

Pero, si en cambio el Verbo ya está presente en medio de todos los pueblos a manera de "semilla", la primera actividad del misionero debe ser la de descubrir esta presencia. Es un trabajo paciente y minucioso, que implica un profundo conocimiento de la cultura. Se trata de estudiar las creencias y observar los ritos que manifiesten la existencia de una apertura a la trascendencia. El "otro" no puede ser visto como un simple destinatario de un endoctrinamiento, sino como contraparte de un diálogo.

Es en las mitologías que los pueblos han plasmado su cosmovisión, conocerlas es algo imprescindible para emprender este diálogo. No es un trabajo sencillo, no sólo es necesa- 
rio dominar el idioma, sino conocer también sus formas arcaicas, los matices poéticos y el uso de las metáforas.

El salesiano Siro Pellizzaro del Vicariato Apostólico de Méndez dedicó toda su vida al estudio de la mitología shuar.

Grabó por años los mitos narrados por los ancianos. Llevó decenas de cuadernos de transcripciones y de traducciones.

A la luz de los nuevos planteamientos teológicos empezó a desarrollar nuevas hipótesis. Si Dios está presente en este caminar de los pueblos ¿sus mitologías no podrían considerarse como su Antiguo Testamento?

La idea era tentadora y el mismo padre comenzó a desarrollar una catequesis partiendo de esta perspectiva. Le guiaba además otra preocupación. La pastoral anterior pedía a los Shuar que abandonaran sus creencias, su cultura, su manera de ser, para hacerse cristianos. En la práctica se les exigía que abandonaran su identidad para tomar como punto de referencia al mundo blanco-mestizo. De esta manera, el Evangelio dejaba de ser "una buena noticia" para convertirse en un llamado a negar los valores tradicionales.

Todos estos planteamientos tenían su lógica, pero implicaban un cambio demasiado repentino y radical. A los mismos shuar cristianos les movió el piso. Entre los misioneros comenzaron discusiones encendidas. ¿No se acababa desvalorizando el Antiguo Testamento, reduciéndolo a una mitología entre tantas? Usando un vocablo de la mitología shuar para designar a Dios. ¿no se corría el riesgo de crear peligrosas confusiones?

Como varios salesianos del Vicariato Apostólico habían frecuentado cursos de misionología en la Universidad Gregoriana de Roma, pensaron acudir a uno de sus maestros más apreciados, el P. Joseph Goetz, s.j. Fue así que se le dirigió una carta, en busca de sus reflexiones.

La que aquí se reproduce es su respuesta. Hay que tener en cuenta que, más que teólogo, el P. Goetz era antropólogo, pero no se puede negar que sus reflexiones de tipo teológico son muy interesantes.

Muchos se preguntarán a qué viene la publicación de un escrito de hace 32 años.

Es que la discusión sobre el valor salvífico de las religiones no cristianas es más actual que nunca y la discusión anda muy lejos de aplacarse. En estos años se ha enriquecido con nuevos matices y ha pedido continuas intervenciones del magisterio eclesial. Paul Knitter observa que hoy hay tantos puntos de vista, que resultan casi tan numerosos como las religiones mismas. 
El jesuita Michel Fédou hace notar que ninguna otra era de la teología, en los últimos años, ha conocido un desarrollo tan amplio y rápido como la teología de las religiones y el diálogo religioso.

Es fácil comprender el por qué. Tantas guerras actuales tienen una motivación o, por lo menos, un trasfondo religioso: hay que buscar la manera de encontrarse. Si todas las religiones constituyen una búsqueda del mismo Dios, no puede ser que, a lo largo del camino que lleva a Él, los hombres se vayan matando en su nombre.

Se dirá que esto vale para las "grandes religiones" del mundo, pero que no es lo mismo, si se habla de un pequeño pueblo amazónico como el shuar.

Existen pueblos poco numerosos, pero no existen religiones "pequeñas". En el último rincón de la selva uno se puede topar con los problemas existenciales que hay en las metrópolis. En un sitio, como en el otro, viven seres humanos.
Antropólogos y misioneros: presupuestos de un desacuerdo, Antropólogos y Misioneros: una confrontación insuperable

\section{Marie-Astrid Dupret ${ }^{1}$}

$\mathrm{Al}$ leer la carta que el profesor Joseph Goetz escribe al P. Juan Bottasso en respuesta a sus preguntas respecto a la catequesis de los Shuar y las posibles comparaciones entre la mitología de este pueblo de la Amazonía y el Antiguo Testamento, el primer comentario que quisiera hacer es recalcar la importancia atribuida por Goetz a las profundas diferencias que existen entre las creencias de esta sociocultura "primitiva"2 y las del mundo cristiano.

En este sentido, pienso que Goetz, gran antropólogo y a la vez, experto en Religiones Comparadas, pone de relieve la necesidad de no incurrir en equivalencias simplistas y de distinguir en todas las construcciones religiosas sus valores específicos y estructurales únicos. De hecho una asimilación superficial de unas deidades con otras de otro contexto cul-

\footnotetext{
Doctora en Filosofia y Letras, Universidad de Lovaina, Psicoanalista.

Personalmente, me gusta mantener el vocablo de 'primitivo' para referirme a los pueblos que viven todavía en grupos restringidos en cuanto resalta el aspecto menos elaborado, menos sofisticado, y a la vez más auténtico de estos grupos humanos que aún son partes de socioculturas donde todos los integrantes se conocen los unos a los otros (o por lo menos dentro de los subgrupos), de modo que representan las formas iniciales de las sociedades humanas.
} 
tural tiene como consecuencia desnaturalizar la cosmovisión y la dinámica tanto discursiva como gestual propias de cada grupo étnico así como su manera singular de definir los valores éticos esenciales de su organización sociocultural. A propósito de esto, Goetz hace hincapié en "el problema del lenguaje" que él mismo amplia al nivel de 'sistema de expresión’ o, diríamos, de sistema simbólico.

Pero de ninguna forma tal individualización del montaje religioso de cada grupo puede llevar a pensar que no existen linderos que permitan comunicaciones ni tampoco a excluir la presencia de estructuras comparables, lo que ciertamente no ignora Goetz, quien siempre reconoció su deuda con Mircea Eliade. En este sentido, si se quiere promover una catequesis que no sea alienante $o$ colonizadora, el establecimiento de estos puentes parece indispensable, aunque exija el apoyo de mediaciones sincréticas ${ }^{3}$.

Lo que me parece menos convincente en la carta de Goetz y, tengo que reconocerlo, incluso llamativo por parte de alguien que compartió mucho tiempo con sociedades tradi- cionales y pueblos primitivos es su interpretación unívoca de lo que llama la "dignidad de Dios" como "potencia total" y, sobre todo, su lectura de la salvación por Cristo.

Por cierto, la figura de Cristo Salvador de la humanidad entera aparece dentro de un contexto histórico determinado, aunque no hay que olvidar que otras figuras bastante similares -no digo idénticas- surgieron en el Medio Oriente en esta época entre las cuales cabe recordar dentro del Cristianismo mismo a San Juan Bautista. Por otro lado, el "monoteísmo fanático" que Goetz atribuye al pueblo judío es una convicción que, como él mismo lo reconoce, se elaboró durante largos siglos. Investigaciones arqueológicas recientes indican en los niveles bíblicos más antiguos en Tierra Santa la presencia de una diosa femenina al lado del Dios de los patriarcas y los Exegetas admiten que en los primeros tiempos históricos de la Biblia, se consideraba a Dios no como un dios único sino como el más potente. Todo esto, Goetz lo menciona en su carta pero no saca las conclusiones que me parecen adecuadas en cuanto a la evolución del monoteísmo como

3 A menudo se ha considerado el sincretismo como un intento de enmascarar a la pureza de una expresión religiosa. A mi parecer, se trata más bien de un esfuerzo de dialectizar e integrar nociones nuevas. 


\section{A propósito de una carta de Joseph Goetz a Juan Bottasso}

reflejo de un pensamiento cada vez más depurado a partir de la creencia en un Dios único, omnipotente y atemporal, desligado de la historia. No es el espacio para discutir aquí cómo un hecho histórico como la muerte de Cristo en Jerusalem en una época determinada reviste el valor de salvación universal, lo que me parece la tarea de los teólogos cristianos.

Sin embargo, queda abierta la cuestión de los pueblos que han vivido ajenos a esta vivencia religiosa dentro del marco de una evolución muy diferente. Por un lado, Goetz descarta, a mi parecer de manera errónea, la idea de un dios creador entre los Shuar por no tener en su panteón a un ser "superior a los demás". Al leer Eliade, no hay duda que todos los puebles selváticos se han forjado una noción de un dios uránico; y hay que recordar que los Shuar tienen una astronomía y una mitología cósmica muy desarrolladas. Pero ha ocurrido en la mayoría de estos casos que los dioses uránicos se han retirado lejos del mundo terrenal, abandonando a su creación a su suerte de enfermedades y muerte. De modo que la conceptualiza- ción de un tiempo paradisíaco al origen, es una idea muy extendida para no decir universal. Menos común es la razón aducida respecto a la causa del fin de in illo tempore de paz y armonía que, en los grupos primitivos, no suele plasmarse en la idea de un pecado originario.

En cuanto a la creencia en la redención por la muerte de Cristo que está en el corazón del cristianismo, sin restarle su valor universal, aparece bajo la forma de una explicación religiosa relativamente tardía. No ahondaré en este tema pero lo que sí me parece interesante y que cuestiona los comentarios de Goetz respecto a la "Salvación", es citar aquí la reflexión de muchos religiosos cristianos de gran valor espiritual quienes, a su llegada a América en la época de la Conquista, interpretaron la bondad, la honestidad y la generosidad de los pueblos nativos como sociedades que vivían todavía en tiempos antes de la caída por el pecado originario, antes de la expulsión del paraíso terrenal ${ }^{4}$. Entonces surge la pregunta: ¿Acaso seremos nosotros los que les hemos aportado el pecado y la maldad y, de allí, la necesidad de la salvación por Cristo? 
Una última nota a propósito de la carta. Goetz termina llamando la atención respecto a la peligrosa idea, según él, de la fecundación de una mujer por el efecto de un espíritu; esta observación viniendo de su parte es muy curiosa. Para el cristianismo, no cabe duda que más allá del acto sexual, todo niño está dotado de un alma por efecto de Dios y que el ejemplo más simbólico de este momento es el de la virgen María visitada por el Santo Espíritu. Sin cuestionar el sentido del nacimiento divino de Cristo, me parece inadmisible atribuir valor sólo a las creencias que pertenecen al contexto sociocultural de los dominantes y denigran las de los otros, poniendo en duda de manera algo simplista la posibilidad de "hacer surgir la idea de Dios en unas mentes animistas", como si el Cristo cristiano se dirigiera exclusivamente a ciertos pueblos elegidos, abandonando a los otros en un estado de retraso mental que no les permitiría acceder a la palabra evangélica si no es renunciando a sus valores éticos propios.

\section{José Sánchez-Parga ${ }^{5}$}

Nunca en los cursos de Goetz aparecía el antropólogo en disputa con el misionero, pero en esta carta es el antropólogo quien se muestra derrotado por el misionero cristiano. Si esta carta me descubre un Goetz desconocido, es porque el profesor de antropología no se refería en sus clases al cristianismo ni a la Biblia, ni tampoco hacía misionología. De hecho el texto de su curso (Cosmos, Roma 1968) se basaba en una idea fundamental: la verdad de los mitos corresponde a la fuerza de las creencias que ellos mismos producen; y constituía una invitación a pensar las creencias cristianas desde los mitos ("el Héroe y el Hijo", "la Madre y la Virgen").

Es cuando Goetz se pone a pensar "el trabajo de campo" no del antropólogo sino del misionero, que incurre en etnocentrismos muy simplistas; como el que África, atrapada por sus mitos, no ha entrado todavía en la historia, o que sólo el monoteísmo judeo-cristiano funda la única verdadera experiencia religiosa de todos los pueblos. Goetz parece ignorar: a. Que la experiencia religiosa es siempre un "hecho total" (Malinowski) para un pueblo y por consiguiente sólo inteligible y justificable desde la totalidad sociocultural de dicho pueblo; y $b$. Que el monoteísmo por 
razones muy complejas se desarrolla estrechamente vinculado a la experiencia religiosa del Libro; razón que lo hace difícilmente universalizable o transferible a otros pueblos.

En este sentido Goetz parece olvidar que la larga historia del pueblo hebreo supuso profundos cambios no sólo en su experiencia religiosa sino también en su misma representación de Dios: una era la religión y el Dios de los patriarcas, otra muy diferente, la religión y el Dios mosaico; más diferente sería después la experiencia religiosa que el pueblo hebreo desarrolla a partir del Templo de Jerusalem, de los profetas, y el que conoció Jesucristo; finalmente, los cambios religiosos impuestos al judaísmo por una diáspora milenaria por todo el mundo. Las vicisitudes históricas de la experiencia religiosa cristiana, así como los cambios culturales debidos a su expansión en el mundo, hicieron que también el cristianismo sufriera profundas transformaciones. A pesar de la fuerza de sus dogmas, del poder doctrinario, de su jerarquía y centralismo institucionales, el catolicismo ha cambiado tanto en el transcurso de los últimos 500 años como ha sido grande su diversificación por todos los pueblos del mundo.

No es casual que frente a las transformaciones históricas y socio- culturales hayan sido precisamente las religiones del libro (judíos, cristianos y musulmanes), las que se hicieron doctrinarias, dogmáticas y fundamentalistas para resistir a los cambios.

Goetz sostiene, con acierto, que las religiones primitivas ni corresponden ni pueden ser traducidas a la religión bíblica o cristiana. Pero con la misma razón habría que sostener que ni el cristianismo ni la experiencia religiosa de la Biblia son traducibles a las religiones primitivas. El "mesianismo" judeo-cristiano, la "soteriología" o idea de salvación tanto como la "escatología" cristianas con su idea de un "más allá" de este mundo y de la historia no son esenciales a la experiencia religiosa y por consiguiente tampoco universalizables.

Goetz parece menospreciar la mitología de las religiones primitivas. Sin embargo, en la década de los setenta, ningún pensador, antropólogo o teólogo, familiarizado con el mundo de los estudios bíblicos podía ignorar el programa de la desmitologización (Entmythologisierung), que el gran exegeta y teólogo protestante Rudolf Bultman, proponía para comprender el Antiguo y el Nuevo Testamento, planteando que fue en base a un enorme acervo mítico, que se construyó la experiencia religiosa tanto del pueblo hebreo como de los 
orígenes cristianos. La pregunta que desde entonces podría plantearse es si cualquier experiencia religiosa puede elaborarse al margen de una simbología y una mitología; y en qué medida la misma experiencia religiosa cristiana se encuentra desprovista de esta carga simbólica y mitológica. Lo que a su vez obliga a reconocer cuánto la mitológica y simbólica religiosas se encuentran investidas de las tradiciones culturales de un pueblo.

El programa de la desmitologización de Bultman abrió el Antiguo y Nuevo Testamento al campo de los estudios antropológicos, los cuales sin embargo fueron muy limitados por razones doctrinales, y por ello insuficientes para alimentar e iluminar el trabajo de los misioneros cristianos.

Ahora bien, si una experiencia religiosa es siempre parte esencial de la tradición cultural de un pueblo, cabría sostener que tales experiencias religiosas propias de un pueblo son intransferibles a otros pueblos. Lo que haría imposibles las conversiones de una religión a otra. Fenómeno éste, que la experiencia histórica ha contradicho con extraordinaria frecuencia: siempre hubo conversiones de una religión a otra a pesar de las diferentes tradiciones culturales.
Es en esta precisa y fundamental cuestión, que la antropología proporciona un extraordinario aporte teórico: por muy diferente que sean dos culturas, por muy distantes que sean histórica y espacialmente dos tradiciones culturales, por el hecho de que se trata de culturas humanas, siempre es posible entre ellas ese RECONOCIMIENTO (la An-erkennung hegeliana), que supone reconocerse en la otra cultura e identificarse con ella: reconocer (intelectualmente) el sentido de la otra cultura (o de la otra religión), supone compartir (prácticamente) dicho sentido con el pueblo que pertenece a tal cultura, e identificarse (afectivamente) con ambos.

Lo que un antropólogo más hegeliano y levi-straussiano que goetziano podría aconsejar a los misioneros hoy y siempre es precisamente esta teoría del reconocimiento y práctica de la identificación con el otro, tan profundamente antropológicas y éticas como cristianas. Lo cual comporta otro postulado que los misioneros tienden a olvidar y que para los antropólogos es un presupuesto: una experiencia religiosa, como la cultura, lejos de ser enseñada sólo puede ser transmitida. 